\title{
Exploring the Relationship Between Students' Perception, Interest and Mathematics Achievement
}

\author{
Anas Seidu Salifu ${ }^{1 *}$ (D), Adamu Bakari ${ }^{2}$
}

${ }^{1}$ E.P. College of Education, Bimbilla, GHANA

${ }^{2}$ Bole Senior High School, GHANA

*Corresponding Author: salifuanas@gmail.com

Citation: Salifu, A. S., \& Bakari, A. (2022). Exploring the Relationship Between Students' Perception, Interest and Mathematics Achievement. Mediterranean Journal of Social E Behavioral Research, 6(1), 13-20. https://doi.org/10.30935/mjosbr/11491

\begin{abstract}
The purpose of this study was to explore the relationship between students' perception, interest and mathematics achievement using purely quantitative approach. The research design used was descriptive survey. The study adopted purposive and simple random sampling techniques to choose a sample of 232 senior high students. The instruments used were questionnaires for measuring students' perception and interest and achievement test. The results were analysed using descriptive and inferential statistics. The results revealed that students had negative perception towards mathematics and positive interest towards mathematics. Also, the results revealed that student's interest and perception significantly predicted students' achievement in mathematics. Again, a positive, moderate and significant relationship was recorded between students' interest and achievements in mathematics. Furthermore, there was a positive weak correlation between students' perception and achievement in mathematics which is also significant. Finally, weak positive significant correlation was recorded for the relationship between students' perception and interest towards mathematics.
\end{abstract}

Keywords: perception, interest, achievement, relationship, correlation

Received: 9 Oct. 2021 Accepted: 29 Nov. 2021

\section{INTRODUCTION}

Mathematics is the heart of science and its related courses, without mathematics there is no real development in science and technology (Hafiz \& Hina, 2016). The competence gained in the study of mathematics is widely known and used in all spheres of human life (Asiedu-Addo \& Yidana, 2004). Mathematics plays a very key role in shaping how individuals deal with the various spheres of private, social, and civil life (Walshaw \& Anthony, 2009). Mathematics is seen by society as the basis of scientific knowledge that is very important in socio-economic development of a nation (Reeve, 2013). According to Kalhotra (2013), mathematics is one of the most important subjects which act as a bridge to all sources of knowledge. This was intensified by Federal Republic of Nigeria (FRN) National Policy on Education 6th edition (2013) in which mathematics was clearly stated and noted as a necessary requirement for any science related fields of study such as engineering, chemistry, health sciences (Medicine, nursing, and optometry), and the social sciences (communication, economics, and geography). Despite the importance of mathematics to students' careers and its relevance to everyday life, there are a number of observable problems associated with its teaching and learning, especially at the senior high school level. Researchers find it very important to investigate why students still fail in mathematics.
The findings of this study will be of great benefit to students, mathematics teachers, the school administrators, policy makers in education and government. Policy makers are expected through this study to realize the importance of students' interest in mathematics and its influence in their mathematics achievement. Therefore, the study will help improve educational policies that will boost student's interest in mathematics. The findings of the study will contribute to the existing body of knowledge in the area of mathematics in the district as well as other areas. Findings from this study would be very useful to students, teachers and other stake holders in the educational sector to identify teacher-efficacy as a positive contributor to students' interest and achievement in mathematics. It will also be of benefit to educationists as it will open more research gaps for future research in the field of mathematics education. The views from various mathematics students will enrich teaching approaches, identify and give a probable and workable solution to some of the problems facing them in teaching and learning of mathematics. The research findings will be of benefit to mathematics teachers as it will guide them to improve on their method of delivering lessons as well as improving students' mathematics achievement. When teachers understand that learning is not a "onesize-fits-all" approach, it will make it easier for teachers to teach to the strength of their individual students and ensure that mathematics stays on the cutting edge tomorrow. 
In Ghana, some of the objectives of learning mathematics at the senior high schools are, as follows: (a) To develop computational skills of students by using suitable method to perform calculations. (b) Students should be able to recall, apply and interpret mathematical knowledge in the context of everyday situations. (c) Learners should develop the ability to translate word problems into mathematical language and solve them with related mathematical knowledge or ideas. (d) They should be able to organize, interpret and present information accurately in written, graphical and diagrammatic forms. (e) Students should use mathematical knowledge and other instrument to measure and construct figures to an acceptable degree of accuracy. (f) Learners should develop precise logical and abstract thinking ideas. (g) They should be able to analyse a problem, select a suitable strategy and apply an appropriate technique to obtain its solution.

\section{LITERATURE REVIEW}

Perception is the process of selecting, organizing, and interpreting data gathered by our senses in order to comprehend the world around us (Greenberg \& Baro, 1999, p. 72). The teacher's attitude and teaching technique can have an impact on students' perceptions. The way pupils see mathematics is determined by what they believe mathematics is all about. Mathematical perception refers to a person's interest in or feelings about the subject. Students' interest towards Mathematics learning has a great implication for Mathematics lesson instruction among mathematics teachers at all levels of the educational ladder. Students interest towards Mathematics participation is a significant factor towards students' success in mathematics.

\section{Studies on Students' Perception Towards Mathematics}

Students' positive perceptions of mathematics were greatly influenced by the teacher's method of mathematics teaching and his personality, according to studies conducted in Australia, and that students who lack interest and personal effort in learning mathematics are unlikely to perform well in the subject (Koul \& Fisher, 2006).

According to the findings of a study conducted in various Nigerian schools, students' attitudes toward mathematics are favorable, and many of them believe that mathematics is a valuable and necessary subject that would benefit them in their future careers (Olatoye, 2002). Perceptions of mathematics are generally positive, according to Koul and Fisher (2006). Ampadu (2012) in a study indicated that the influence of students' perceptions towards mathematics showed that the teacher's method of teaching mathematics and his personality greatly accounted for the students' positive or negative perception towards mathematics. Ampadu also stressed that students' beliefs and perceptions have the potential to either facilitate or inhibit learning.

Hagan et al. (2020) concluded that students have positive perception towards mathematics when they used 297 students selected via stratified sampling with questionnaire as the main instruments for collecting data in Ghana. Similarly, Daud et al. (2020) purpose was to examine students' perceptions in learning mathematics and how these perceptions contributed to problems in comprehending mathematics among some selected Malaysian Secondary School students. Their study results showed that there was a positive perception towards Mathematics, and a statistically significant relationship between students' perceptions towards mathematics and their mathematics grade using APOS Theory. Furthermore, Arthur et al. (2017) investigated student perception and its impact on Ghanaian students' interest in mathematics. The study established that $58.1 \%$ of total respondents agreed that students' negative perception of math strongly influences their interest in math as they progressed in their studies. In another vein, Kabeera (2018) carried out a study to examine the influence of students' perception on mathematics, the results revealed that student's perception on mathematics either positively or negatively influence their mathematics interest as well as their general mathematics performance. Similarly, Mariam et al. (2016) carried out research on students' perception toward mathematics performance. According to the study's findings, the manner in which Mathematics was being handled by tutors during the process of teaching and learning is the first source of the students' perception toward mathematics. The findings also pointed out that students' perceived mathematics as not useful in their lives and hence no need to develop an interest for it.

\section{Studies on Students' Interest About Mathematics}

A study was conducted by Leonard (2016) on factors affecting students' interest in mathematics in secondary schools in Enugu State. The research findings revealed that, teacher factor, student factor, instructional strategy, mathematics anxiety and infrastructural problem correlated positively with students' interest and their mathematics achievements. Also, in Rimma (2017), the purpose of the study was to investigate how interested and engaging students are, in a mathematics class, and the perception they had about mathematics during the lesson. The results showed that few students indicated that interest is manifested through their engagement in mathematics lessons with a positive perception. The findings also showed that students' interest and engagement was developed by teachers during classroom interaction as perceived by the students in mathematical tasks. Similarly, Mohamed and Charles (2017) conducted research on students' interest in mathematics and academic achievement of high school. The findings showed that there was a significant difference in interest in mathematics and academic achievement of high school level students in respect of their type of management. The study found that there was no significant difference between rural and urban area school students at high school level in respect of their interest and their achievement in mathematics.

Relationship of Students' Perception Towards Mathematics and Their Achievement in Mathematics

In their findings on perceptions, Ma and Xu (2004), Muijs and Reynold (2002), and Silver et al. (2009) found that there were very positive attitudes or perceptions towards mathematics in countries like Rwanda and Australia where there was an emerging thirst for students perceptions of mathematics and academic achievement. However, the data revealed that perceptions of mathematics were more neutral in nations with a high degree of technical and industrial growth. In a descriptive survey design, Hagan et al. (2020) reported that there was a very weak and negative relationship between students' perception and achievements in mathematics when they used 180 males and 117 females as the sample. Similarly, Daud et al. (2020) who examined students' perceptions in learning mathematics and how these perceptions may contribute to problems in comprehending mathematics among some selected Malaysian secondary school's students. Their study results showed that there was a positive perception towards Mathematics, and that there was a significant statistical relationship between students' perceptions towards mathematics and their mathematics grade using APOS Theory. As cited 
earlier, Olatoye (2002) found that students' perceptions of mathematics had a significant direct influence on their performance in the subject. Furthermore, Nardi and Steward (2003) state that students' perceptions of the value of learning mathematics can be considered both as input variables and as outcome variables because their perceptions of these subjects can be associated with academic achievement in a way that reinforces the highest or the lowest results. Furthermore, Ahmad et al (2017) conducted a study to investigate the relationship between students' perception toward the teaching and learning methods of mathematics' lecturers and their achievement in pre-university studies. The findings revealed that there was no significant correlation between the average scores of students' perceptions of teaching and learning towards the mathematics lecturers with the average scores of mathematics achievement of the students. The study also revealed that there were no significant differences between the average scores of male and female students' perceptions of the effectiveness of teaching and learning of the mathematics lecturers. The findings of this study showed that the lecturers could improve their teaching skills and techniques which were appropriate to the students' level.

Relationship of Students' Interest Towards Mathematics and Their Achievement in Mathematics

Arthur et al. (2014) purpose was to investigate the variables perceived to influence students' interest in learning mathematics and the extent to which these variables affected students' interest in learning mathematics. Nonetheless, it also investigated factors affecting Ghanaian students' interest in mathematics to enrich their mathematics potentials. The findings from the study revealed that student's interest in mathematics is dependent on whether students liked mathematics as a subject. The teachers' motivation and access to textbooks was also identified to have very positive impact on student interest in mathematics as well as the method and approach adopted by the teacher during teaching and learning of Mathematics. However, the age of students, the type of school attended by students was found to be independent on the students' interest in mathematics.

In another study by Mohammed and Charles (2017), whose purpose was to investigate students' interest in mathematics and their academic achievement, found that there was no significant difference between rural and urban area school students of high school level in respect of their interest and their achievement in mathematics. Similarly, a study was conducted by Leonard (2016), purpose was to find the possible factors that affected students' interest in mathematics. The research findings revealed that teacher factor, student factor, instructional strategy, mathematics anxiety, and infrastructural problem correlated positively with students' interest and their mathematics achievements. Also, Rimma (2017) whose purpose was to investigate how interested and engaging students were in a mathematics class and the perception they had about mathematics during the lesson. The results indicated that students showed less interest in mathematics due to inappropriate methodology used by teachers and few also testified that interest is manifested through their engagement in mathematics lessons with a positive perception. The findings also showed that students' interest and engagement was developed by teachers during classroom interaction. The study concluded that students' interest and engagement had a very significant relation with mathematics classroom achievement. Also, a study conducted by Madeleine (2013) examined the correlation between fifth grade students' attitudes towards mathematics and their achievement in the subject. The findings from a Pearson correlation that was conducted indicated that there was a positive relationship between students' attitude towards mathematics and their mathematics achievements.

Relationship of Students' Perception About Mathematics and their Interest Towards Mathematics

Arthur et al. (2017) aimed at addressing the effect of students' perception and its impact on students' interest in mathematics, using multivariate statistical techniques. The study established that $58.1 \%$ of the total respondents agreed that, students' negative perception of mathematics has strong influence on their interest in mathematics as they moved forward on their educational ladder. The results further indicated that the relationship between student perception and interest in Mathematics was statistically significantly.

The overview of the relevant literature describes differing opinions and results on students' perceptions of mathematics and their achievements. A critical review of the above studies indicated that there are positive reports about the relationship between student perception, student interest, and student academic achievement. It is against this background that the present study also examined the influence of perception and interest on student achievement in math at Bole High School.

\section{THEORETICAL FRAMEWORK}

It is the 'blueprint' or guide for research (Grant \& Osanloo, 2014). It is a framework based on an existing theory in a field of inquiry that is related and/or reflects the hypothesis of a study. Therefore, the theory that underpins this study is the adaptation of Bandura (1986) cognitive theory based on students' perception and their interest on mathematics achievement.

Perception has to do with the individuals' feelings about, or appraisal of, a given object, thing or a person based on the individuals' past and present experiences. According to Bandura (1986), nothing is more powerful than having a direct experience with something. Therefore, students who have excelled in mathematics in the past will definitely have a good perception and interest in learning mathematics leading to high performance. Nevertheless, the interest of the students allows the students to process the understanding of the concepts through different modalities based on their own experiences. Theoretical deliberations about interest development proposed by Baumert and Koller (1998), Hidi (2000), Krapp (2000), and Schiefele (2001) concur in predicting interest declines from childhood through to adulthood. These theorists all seem to agree that interest develops based on observations. Therefore, through vicarious experience, students observe people around us, especially students consider these people their role models or seeing people similar to themselves who have excel in mathematics give students the good perception and interest in mathematics to persevere in learning mathematics leading to high mathematics achievement.

Verbal persuasion or motivation is related to both interest and the desire to learn mathematics (Guy et al., 2015). Students are intrinsically motivated to learn mathematics if they have the desire to do so after finding learning of mathematics interesting (OECD, 2013). It is believed that motivation is the driving force for learning (Yunus \& Ali, 2009). Therefore, when influential people such as teachers, lecturers, parents, etc. strengthen our interest by giving students a good 
perception about mathematics will lead to high mathematics performance. Lastly, physiological and emotional state: the state of a student influences his/her perception as well as interest in learning mathematics. For instance, depression can dampen student's interest in leaning mathematics where as positive emotions will increase students' interest in learning mathematics.

\section{Purpose of the Study}

The purpose of the study was to explore students' perception about mathematics and the interest students have for mathematics. The study also sought to examine the relationship between students' perception, interest as well as students' mathematics achievement.

Objectives of the Study

The study was guided by the following specific objectives:

1. To explore students' perception about mathematics,

2. To explore students interest towards mathematics, and

3. To explore the relationship between students' perception, interest and their mathematics achievement.

\section{Research Questions}

This study sought to find answers to the following questions:

1. What is the perception of students about Mathematics?

2. What is the interest of students towards Mathematics?

3. What is the relationship between students' perception, interest and achievement of mathematics?

\section{Research Hypotheses}

To achieve three research questions of the study, the following hypotheses were tested:

H1: Students' perception about mathematics significantly influences their achievements in mathematics.

H2: Students' interest in mathematics significantly influences their achievement in mathematics.

H3: Students' perception about mathematics significantly influences their interest in mathematics.

\section{METHODOLOGY}

This study adopted descriptive correlation survey design with pure quantitative techniques. According to Emaikwu (2012) who indicated that correlation survey is about establishing relationship between two or more variables. Hence, this design was appropriate in view of the conditions or relationships that exist among perception, interest and achievement in mathematics. The target population of the study was form two and three students at Bole Senior High School. Purposive sampling method was used to select the school while Simple random sampling technique was used to select 232 students ( 99 females and 133 males). The simple random sampling technique ensured that each member of the target population had an equal and independent chance of being included in the sample. The Research Instruments used were Mathematics Achievement Test (MAT) and student's perception and Interest in Mathematics Questionnaire (SPIMQ). The Mathematics Achievement Test (MAT) was set by the researchers which composed of thirty (30) multiple choice items. Also, the Students' perception and Interest in Mathematics Questionnaire (SPIMQ) was adapted from Jang et al. (2009) by the researchers which composed of 20 items which reflected students' perception and interest towards mathematics. The items were rated on 5 Likert-scales, starting from Strongly Disagree $(S D)=1$, Disagree $(D)=2$, Undecided $(U D)=3$, Agree $(S A)=4$, and Strongly Agree $(A)=5$ for students to tick with respect to their opinion. The two instruments were given to three experts in Mathematics Education who have taught mathematics over 10 years for scrutiny and vetting. Their recommendations were the basis for its validation and administration. A pilot study was conducted using the achievement test and the questionnaire in Sankore Senior High School in Asunafo South District to save time and resources. The school also have a similar characteristic as that of Bole Senior High School. The purpose of the pilot study was to ensure validity and reliability of the instruments. Kuder-Richardson formula 20, was used to compute the reliability of the test which yielded 0.86 . This figure indicated that the test was good for the main study. Also, Cronbach alpha was used to determine the reliability of the questionnaires, and coefficient of 0.91 was obtained which showed that the items were reliable and could be administered for main study.

\section{Procedure for Data Collection}

One of the researchers visited the selected school with the consent letter seeking permission from the headmaster on consent and cooperation of the students in the school. The researchers after being given the approval to conduct the study addressed the students on the purpose and relevance of the study. After a week of the initial visit the researchers distributed copies of the test and questionnaire to the students participating in the study. The information that the researchers received during the period of this study was treated confidentially and purely for academic purposes. The researchers waited for the completion of the test and the questionnaires which was done within 1 hour 30 minutes.

\section{Data Analysis}

The data gathered were organized and keyed into SPSS for analysis. Both descriptive and inferential statistics were employed. The descriptive statistics (i.e., frequency distribution, percentages, means and standard deviations) were used to address the research questions one and two, whereas the inferential statistics (Pearson moment correlation) was used to analyse the research question three and the hypothesis.

\section{RESULTS}

This section presents the results of the analysis of the research questions and hypothesis raised for this study.

\section{Analysis of the Research Questions}

Research question 1 (What is students' perception about mathematics?) borders on students' perception about mathematics. The results are presented in Table 1.

From Table 1, the results indicated that mathematics is abstract and boring with (mean=2.10, $\mathrm{SD}=1.33$ ). Also, the students responded that mathematics is very complex to their understanding with (mean $=3.07$, $\mathrm{SD}=1.41)$ Again, with regards to the statement, mathematics has nothing to improve in my life, yielded a (mean $=1.65, \mathrm{SD}=1.08$ ). Moreover, on the issue mathematics is meant for students who are talented and higher achievers it resulted in a $($ mean $=1.90 \mathrm{SD}=1.25)$. 
Table 1. Descriptive statistical analyses of students' perception construct

\begin{tabular}{|c|c|c|c|}
\hline S/No & Statement & Mean & SD \\
\hline 1 & Mathematics is abstract and boring. & 2.10 & 1.330 \\
\hline 2 & Mathematics is very complex to my understanding. & 3.07 & 1.408 \\
\hline 3 & Mathematics has nothing to improve in my life. & 1.65 & 1.079 \\
\hline 4 & Mathematics is full of rules and procedures. & 3.94 & 1.140 \\
\hline 5 & Mathematics is meant for students who are talented and higher achievers. & 1.90 & 1.251 \\
\hline 6 & Mathematics is not difficult as compared to other subjects. & 2.82 & 1.465 \\
\hline 8 & There are so many formulas in mathematics therefore students cannot do well in mathematics. & 2.33 & 1.369 \\
\hline 9 & Students' misconception about mathematics affects their perception of mathematics. & 2.58 & 1.349 \\
\hline \multirow[t]{2}{*}{10} & Students feel they are not involved in the teaching and learning process. & 3.92 & 1.300 \\
\hline & Grand mean and standard deviation & 2.68 & 1.3100 \\
\hline
\end{tabular}

Source: Field work

Table 2. Descriptive statistical analyses of students' interest construct

\begin{tabular}{|c|c|c|c|}
\hline S/No & Statement & Mean & SD \\
\hline 1 & Mathematics is a very interesting subject. & 3.74 & 1.320 \\
\hline 2 & Students like mathematics because they don't have to memorize it, it could all be figured out. & 3.26 & 1.449 \\
\hline 3 & Students enjoy studying mathematics in S.H.S than any other subjects. & 3.48 & 1.348 \\
\hline 4 & Students will like to avoid mathematics if an option is given. & 2.69 & 1.526 \\
\hline 5 & Students lose interest in mathematics due to the negative misconception held by students. & 3.41 & 1.429 \\
\hline 6 & Students like solving new problems in mathematics on their own. & 2.61 & 1.490 \\
\hline 8 & Students dislike mathematics due to its complex nature. & 3.36 & 1.389 \\
\hline 9 & When students hear the word "mathematics", they have the feeling of dislike. & 3.60 & 0.444 \\
\hline \multirow[t]{2}{*}{10} & Teachers do not involve students in the teaching and learning of mathematics. & 3.32 & 1.384 \\
\hline & Grand mean and standard deviation & 3.20 & 1.320 \\
\hline
\end{tabular}

Furthermore, the students responded that there are so many formulas in mathematics hence they cannot do so well in mathematics with a (mean $=2.33, \mathrm{SD}=1.37$ ), they again indicated that their misconception about mathematic affects their perception towards mathematics with a (mean=2.58, SD=1.35). From the analysis, students have shown negative perception towards mathematics with a grand mean of 2.68 and standard deviation of 1.31. In conclusion, students have negative perception towards mathematics.

Research question 2 (What is students' interest about Mathematics?) examines students' interest towards mathematics. The results are presented in Table 2.

As shown in Table 2, majority of the respondents agreed that, mathematics is a very interesting subject (mean $=3.74, \mathrm{SD}=1.32$ ), others claimed that they enjoy studying mathematics than any other subject with (mean $=3.48, \mathrm{SD}=1.35$ ). Table 2 also revealed that students lose interest in mathematics due to the negative misconception held by students with responses corresponding to (mean $=3.41, \mathrm{SD}=1.43$ ). Again, with regards to when students hear the word mathematics, they have the feeling of dislike yielded a (mean $=3.60, \mathrm{SD}=0.44)$. From this analysis, students have shown positive interest towards mathematics with a grand mean of 3.2 and standard deviation of 1.32 .

To answer the research question 3 (What is the relationship between students' perception, interest, and achievement of mathematics?), the empirical triangular model of students' achievement in mathematics was used for further clarity and confirmation. The results of the study showed that students' interest in mathematics and students' perception of mathematics significantly predicted students' mathematics achievement. This is attributed to the $49.24 \%$ of variations in the students' mathematics achievement. The results further indicated that students' interest in mathematics can explain $28.95 \%$ of variance in student's perception of mathematics while students' achievement in mathematics also explains $40.10 \%$ of variance in students' interest to learn mathematics as indicated in Figure 1. It therefore concluded that there is a significant positive relationship between students' perception about mathematics and their interest in mathematics as well as their achievements in mathematics. Similarly, Table 3 depicts Pearson correlation analyses among students' perception, interest, and mathematics achievement.

\section{Analysis of the Hypotheses}

\section{Influence of students' perception on students'achievement in mathematics}

The hypothesis (H1: Students' perception about mathematics significantly influences their achievements in mathematics.) that student perception influences student math scores was tested at a significance level of 0.01 . The results indicated a significant direct relationship between students' perceptions of mathematics and their math achievement $(\mathrm{r}=0.332, \mathrm{p}<0.01)$ with a coefficient of determination $\left(\mathrm{r}^{2}=0.110\right)$, which is a positive weak correlation. Based on this result the hypothesis stated is upheld.

\section{Influence of students' interest on students'achievement in mathematics}

The hypothesis (H2: Students' interest in mathematics significantly influences their achievement in mathematics.) that students' interest influences their achievement in mathematics was tested at a significance level of 0.01 using correlation. The results of the study suggested that there was a direct moderate positive and statistically significant relationship between student achievement in math and students' interest in learning math $(\mathrm{r}=0.509, \mathrm{p}<0.01)$ with a coefficient of determination of $\left(r^{2}=0.259\right)$. This indicated that students' interest in mathematics accounted for $25.9 \%$ of students' achievement. Hence, the hypothesis is accepted. 


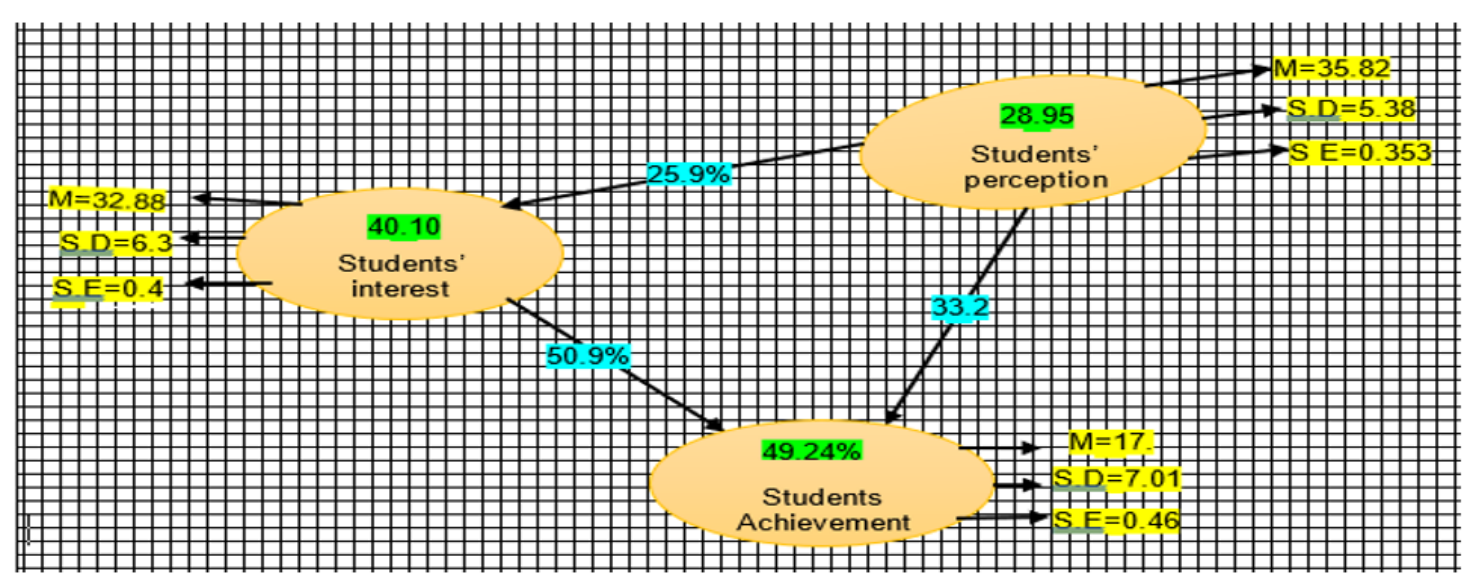

Figure 1. Relationships between students' perception, interest, and mathematics achievements

Table 3. Pearson correlation analyses among students' perception, interest, and mathematics achievement

\begin{tabular}{cccccc}
\hline Construct & Students' perception & Students' interest & Students' achievement & p-value & Cronbach's alpha \\
\hline Students' perception & 1 & 0.259 & 0.332 & 0.000 \\
\hline Students' interest & 0.259 & 1 & 0.509 & 0.000 \\
\hline Students' achievement & 0.332 & 0.509 & 1 & 0.000 & 0.873 \\
\hline
\end{tabular}

${ }^{* *}$ Correlation is significant at the 0.01 level (2-tailed)

\section{Influence of students' perception on students' interest}

The hypothesis (H3: Students' perception about mathematics significantly influences their interest in mathematics.) that students' perception influences their interest tested at a significance level of 0.01 was statistically significant. The findings suggested a direct weak positive relationship between students' perception about mathematics and student's interest towards mathematics at $(\mathrm{r}=0.259, \mathrm{p}<0.01)$ with coefficient of determination $\left(r^{2}=0.067\right)$. That is students' interest in mathematics accounted for $6.7 \%$ of students' perception. Therefore, the hypothesis is accepted.

\section{DISCUSSION}

The findings of the study are discussed here and compared to existing literature. From the analysis of the student's perception towards mathematics was negative. This negative perception was evident because majority of the respondent's indicated mathematics was meant for students who are talented and higher achievers. They also supported their assertion by indicating that mathematics is abstract, boring and has nothing to improve in my life. This finding agrees with the study of (Arthur et al., 2017; Mariam et al., 2016) which also reported students' negative perception towards mathematics. However, it contradicts the findings of Daud et al. (2020) and Hagan et al. (2020) who reported that students have positive perception towards mathematics in their studies.

In another development, students' interest towards mathematics was positive, majority of the students' responses were between disagree and strongly agree. Their interest towards mathematics were supported by their agreement to their responses that mathematics is very easy, enjoyable in senior high school than other subjects. Their disagreement to this statement that when they hear the word "mathematics" they dislike it also affirmed their positive interest towards mathematics. This finding corroborates with the findings of Leonard (2016) and Rimma (2017) who reported that students had positive interest towards mathematics.
From the results it is evident that students' achievement in mathematics accounted for $11.0 \%$ of students' perception. The result of the study suggests that the more positive students experience math, the more likely students will exhibit in mathematics achievement. So, since the students perceive mathematics positively by erasing misconceptions about math, the more students are interested in teaching and learning math, the more math skills will be improved. The more positive perception students have of teaching and learning mathematics will significantly increase their interest in mathematics (Ampadu, 2012). When students receive school counseling to renew their perception of mathematics, they increase their interest in mathematics and have an additional impact on math achievement. The results agree with the views of Arthur et al. (2017a) and Arthur et al. (2014) who also had similar findings. This study is also similar to Madeleine (2013) who also found a positive relationship between students' perception towards mathematics and their mathematics achievement. This study is however opposite to Ahmad et al. (2017) who found no significant correlation between the average scores of students' perceptions of teaching and learning towards the mathematics with the average scores of mathematics achievement of the students.

Also, it is revealed that, when students have interest in the teaching and learning of mathematics, it will further improve their competency in mathematical concepts as well as their confidence level. The more interested students are in the teaching and learning of mathematics, the more it will significantly develop their confidence in studying mathematics as well as their mathematics achievement. However, observations from the study also indicated that when students are guided by mathematics teachers and given academic counselling to eradicate their negative perception about mathematics, it will improve their interest in mathematics and further impact on their achievement and performance in mathematics. This study result agrees with the studies of Arthur et al. (2014) and Arthur et al. (2017b) who found similar results. Also, this study results tallies with that Leonard (2016) who reported that students' interest and their mathematics achievements are positively correlated. Again, this study corroborated with that of Rimma (2017) who also found that students' interest and 
engagement had a very significant relation with mathematics classroom achievement.

From the results of the study, it has revealed that student exhibiting a positive perception of mathematics will further increase their interest in mathematics. Furthermore, the analysis of the study indicated a positive and statistically significant relationship between students' interest and perception to learn mathematics. The results further suggested that the more students are interested in mathematics they will have positive perception to learn mathematics. This study corroborates with Arthur et al. (2017) and Arthur et al. (2014) who also found that, the more positive perception students hold about mathematics will significantly improve their interest in mathematics.

\section{CONCLUSIONS}

Based on this study's results, the students' perception towards mathematics was negative, whereas students' interest towards mathematics was positive. Also, there is a direct statistically significant weak positive relationship between students' perception about mathematics and their achievement in mathematics. Again, the students' perception and interest predicted students' achievement in mathematics. Furthermore, students' interest in mathematics is moderately positive and significantly correlate which influences their achievement in mathematics. Finally, there is a weak positive direct relationship between students' interest in mathematics and their perception about mathematics which is statistically significant.

\section{Recommendations}

1. The study recommends for stakeholders and mathematics educators to engage students in activities that will positively improve students' perception and their interests for learning mathematics.

2. It is recommended that teachers be sensitized on how best they could approach mathematics, relate to students and change the attitude of students on mathematics.

\section{Implications and Suggestions for Further Research Study}

The data collected showed that perceptions and interests of students towards mathematics is determined by various factors. The study has established that students' perception and their interest level influenced the confidence and commitment they had towards mathematics which eventually influenced their mathematics achievement. Although the findings are from the Savanna Region of Ghana, more precisely Bole district, the findings are not generalizable because they represented only an urban area whose population was unique. It is recommended that a similar study should be done in other regions in Ghana so as to unearth more about the influences of students' perception and interest on students' achievement in mathematics.

Author notes: The author approves final version of the article.

Funding: The author received no financial support for the research and/or authorship of this article.

Declaration of interest: The author declares no competing interest.

Data availability: Data generated or analysed during this study are available from the authors on request.

\section{REFERENCES}

Ahmad, A. N., Azizan, F. L., Rahim, N. F., Jaya, N. H., Shaipullah, N. M., \& Siaw, E. S. (2017). Relationship between students' perception toward the teaching and learning methods of mathematics' lecturer and their achievement in pre-university studies. International Education Studies, 10(11), 129-134. https://doi.org/10.5539/ies. v10n11p129

Ampadu, E. (2012). Students' perceptions of their teachers' teaching of mathematics: The case of Ghana. International Online Journal of Educational Sciences, 4(2), 351-358.

Anthony, G., \& Walshaw, M. (2009). Characteristics of effective teaching of mathematics: A view from the west. Journal of Mathematics Education, 2(2), 147-164.

Arthur, Y. D., Asiedu-Addo, S., \& Assuah, C. K. (2017a). Triangular law of students' mathematics interest in Ghana: A Mmodel with motivation and perception as predictor. International Electronic Journal of Mathematics Education, 12(3), 539-548. https://doi.org/10.29333/iejme/630

Arthur, Y. D., Asiedu-Addo, S., \& Assuah, C. K. (2017b). Students' perception and its impact on Ghanaian students' interest in mathematics: Multivariate statistical analytical approach. Asian Research Journal of Mathematics, 4(2), 1-12. https://doi.org/10.9734/ ARJOM/2017/33023

Arthur, Y. D., Oduro, F. T., \& Boadi, R. K. (2014). Statistical analysis of Ghanaian students' attitude and interest towards learning mathematics. International Journal of Education and Research 2(6), 661-670.

Asiedu-Addo, S. K., \& Yidana, I. (2004). Mathematics teachers' knowledge of the subject content and methodology. Mathematics Connection, 4(1), 45-51. https://doi.org/10.4314/mc.v4i1.21500

Bandura, A. (1977). Self-efficacy: Toward a unifying theory of behavioural change. Psychological Review, 84, 191-215. https://doi.org/10.1037/0033-295X.84.2.191

Bandura, A. (1986). Social foundations of thought and action: A social cognitive theory. Prentice-Hall, Inc.

Baumert, J., \& Koller, O. (1998). Interest research in secondary level I: An overview. In L. Hoffmann, A. Krapp, K. A. Renninger, \& J. Baumert (Eds.), Interest and learning: Proceedings of the seeon conference on interest and gender (pp. 241-256). IPN.

Daud, A. S., Adnan, N. S. M., Abd Aziz, M. K. N., \& Embong, Z. (2020). Students' Perception towards Mathematics using APOS Theory: A Case Study. Journal of Physics: Conference Series 1529. https://doi.org/10.1088/1742-6596/1529/3/032020

Emaikwu, S. O. (2011). Assessment of the impact of students' mode of admission into university and their academic achievement in Nigeria. International Journal of Academic Research in Progressive Education and Development, 1(3), 151-164.

Federal Republic of Nigeria National Policy on Education 6th Edition (2013). Nigerian Educational Research and Development Council. https://education.gov.ng/wp-content/uploads/2020/06/ NATIONAL-POLICY-ON-EDUCATION.pdf 
Grant, C., \& Osanloo, A. (2014). Understanding, selecting, and integrating a theoretical framework in dissertation research: Creating the blueprint for your "house". Administrative Issues Journal: Connecting Education, Practice, and Research, 4(2), 12-26. https://doi.org/10.5929/2014.4.2.9

Greenberg, J., \& Baron, A. R. (1999). Behaviour in organisations. McGraw-Hill.

Guy, G. M., Cornick, J., \& Beckford, I. (2015). More than math: On the affective domain in developmental mathematics. International Journal for the Scholarship of Teaching and Learning, 9(2), Article 7. https://doi.org/10.20429/ijsotl.2015.090207

Hafiz, T. J., \& Hina, H. A. (2016). Causes of poor performance in mathematics from teachers, parents and student's perspective. American Scientific Research Journal for Engineering, Technology, and Sciences, 15(1), 122-136.

Hagan, J. E., Amoaddai, S., Lawer, V. T., \& Atteh, E. (2020). Students perception towards mathematics and its effects on academic performance. Asian Journal of Education and Social Studies, 8(1), 8-14. https://doi.org/10.9734/AJESS/2020/v8i130210

Hidi, S. (2000). An interest researcher's perspective on the effects of extrinsic and intrinsic factors on motivation. In B. Sansone, \& J. M. Harackiewitz (Eds.), Intrinsic and extrinsic motivation: The search for optimum motivation and performance (pp. 309-330). Academic Press. https://doi.org/10.1016/B978-012619070-0/50033-7

Jang, S. J., Guan, S. Y., \& Hsieh, H. F. (2009). Developing an instrument for assessing college students' perceptions of teachers' pedagogical content knowledge. Procedia-Social and Behavioural Sciences, 1(1), 596-606. https://doi.org/10.1016/j.sbspro.2009.01.107

Kabeera, P. (2018). Examining the influence of student's perception on mathematics performance: Case of three selected Rwandan secondary schools. International Journal of Research Studies in Education, 1, 33-41.

Kalhotra, S. K. (2013). A study of causes of failure in mathematics at high school stage. Academic Research International, 4(5), 588-599.

Koul, R. B., \& Fisher, D. L. (2006). Students' perceptions of teachers' interpersonal behaviour and identifying exemplary teachers. In Experience of Learning. Proceedings of the 15th Annual Teaching Learning Forum. The University of Western Australia.

Krapp, A. (2000). Interest and human development during adolescence: An educational-psychological approach. In J. Heckhausen (Ed.), Motivational psychology of human development (pp. 109-128). Elsevier. https://doi.org/10.1016/S0166-4115(00)80008-4

Leonard, C. A. (2016). Factors affecting students' interest in mathematics in secondary schools in Enugu state. International Journal of Education and Evaluation, 2(1), 22-28.
Ma, X., \& Xu, J. (2004). The causal ordering of mathematics anxiety and mathematics achievement: A longitudinal panel analysis. Journal of Adolescence, 27(2), 165-179. https://doi.org/10.1016/j.adolescence. 2003.11.003

Madeleine, M. P. (2013). The relationship between attitudes and achievement in mathematics among fifth grade students. Honors Teses, Paper 126.

Mariam, S., Mustapha, W. A. H. W., Farah, S. H. M. K., \& Liziana K. Z. (2016). A Study of Students' Perception toward Mathematic. Journal of Applied Environmental and Biological Sciences., 6(7S), 28-33.

Mohammed, I. B., \& Charles, M. A. A. (2017). Interest in mathematics and academic achievement of high school students in Chennai district. International Journal of Innovative Science and Research Technology, 2(8), 2456-2165.

Muijs, D., \& Reynolds, D. (2002). Teachers' beliefs and behaviors: What really matters? Journal of Classroom Interaction, 50(1), 25-40.

Nardi, E., \& Steward, S. (2003) Is mathematics T.I.R.E.D? A profile of quiet disaffection in the secondary mathematics classroom. British Educational Research Journal, 29(3), 345-366. https://doi.org/ 10.1080/01411920301852

OECD. (2013). PISA 2012 results: Ready to learn:Students' engagement, drive and self-beliefs (Volume III). OECD. https://doi.org/10.1787/ 9789264201170-en

Olatoye, R. A. (2002). Comparison of male and female senior secondary school students' learning outcomes in science in Katsina state, Nigeria. Mediterranean Journal of Social Sciences, 5(2), 517-552.

Reeve, E. M. (2013). Implementing science, technology, mathematics, and engineering (STEM) education in Thailand and in ASEAN. https://docplayer.net/17179389-Implementing-sciencetechnology-mathematics-and-engineering-stem-education-inthailand-and-in-asean.html

Rimma, N. (2017). Interest and engagement: Perspectives on mathematics in the classroom [PhD thesis, University of Gothenburg].

Schiefele, U. (2001). The role of interest in motivation and learning. In J. M. Collis, \& S. Messick (Eds.), Intelligence and personality: Bridging the gap in theory and measurement (pp. 163-194). Erlbaum.

Silver, E. A., Mesa, V. M., Morris, K. A., Star, J. R., \& Benken, B. M. (2009). Teaching mathematics for understanding: An analysis of lessons submitted by teachers seeking NBPTS certification. American Educational Research Journal, 46, 501-531. https://doi.org/10.3102/0002831208326559

Yunus, A. S., \& Ali, W. Z. (2009). Motivation in the learning of mathematics. European Journal of Social Sciences, 74), 93-101. 